\title{
The accuracy of references in paediatric journals
}

\author{
A Vargas-Origel, G Gómez-Martínez, M A Vargas-Nieto
}

\begin{abstract}
We analysed the reference error rate of four paediatric journals. The overall rate was $\mathbf{2 9 . 7 \%}$. Individual rates were as follows: Acta Paediatr 36\%, Arch Dis Child 22\%, J Pediatr 29\%, Pediatrics 32\%; the rate of major errors was $1 \%, 1 \%, 2 \%$, and $4 \%$, respectively.

(Arch Dis Child 2001;85:497-498)
\end{abstract}

Keywords: accuracy; reference; journal

Accurate references in research studies are essential for the transmission of scientific knowledge, so it is imperative that they should be written properly to make searching easy. Furthermore the quality and credibility of the study, the authors, and the journal itself are increased. ${ }^{12}$ Studies on the frequency of reference errors in medical, non-paediatric, journals have been published previously; we believe this is the first study assessing paediatric journals.

\section{Methods}

We assessed 12 regular issues for the year 1999 (supplements excluded), of the following journals: Acta Paediatrica (Acta Paediatr), Archives of Disease in Childhood (Arch Dis Child), fournal of Pediatrics ( $F$ Pediatr), and Pediatrics. All references in the bibliography of each article were numbered consecutively and a sample of 100 references of each journal was selected using a table of random numbers. We excluded nonindexed references and in these cases we chose the immediately preceding or subsequent reference.

We examined each reference and compared them with the original for accuracy, using the following six elements: author(s); study title; name and abbreviation of journal; year; volume; and initial and final pages. Errors were classified as: major-those that make immediate access to the reference particularly difficult, as a result of errors in the publishing year, volume, initial page, or name of the journal; or minor-such as wrong abbreviation for the journal, incorrect title, an author's name missing, wrong citation of the final page, or spelling

Accepted 2 August 2001

Table 1 Errors found in paediatric journal references

\begin{tabular}{lccccc}
\hline & $\begin{array}{l}\text { Acta } \\
\text { Paediatr }\end{array}$ & $\begin{array}{l}\text { Arch Dis } \\
\text { Child }\end{array}$ & f Pediatr & Pediatrics & Total \\
\hline Number of references & 100 & 100 & 100 & 100 & 400 \\
Total number of errors & 36 & 22 & 29 & 32 & 119 \\
$\begin{array}{l}\text { Type of error } \\
\text { Minor }\end{array}$ & 35 & 21 & 27 & 28 & 111 \\
$\quad$ Major & 1 & 1 & 2 & 4 & 8 \\
$\quad$ Volume & 1 & 0 & 0 & 2 & 3 \\
$\quad$ Year & 0 & 0 & 1 & 1 & 2 \\
$\quad$ Initial page & & 1 & 1 & 1 & 3 \\
Number of errors/reference & 30 & 14 & 15 & 24 & 83 \\
$\quad$ One & 3 & 6 & 9 & 6 & 24 \\
$\quad$ Two & 3 & 2 & 5 & 2 & 12 \\
$\quad$ Three or more & & & & & \\
\hline
\end{tabular}

mistakes in any of the above elements. ${ }^{1-3}$ We used descriptive statistics and compared the frequency of errors with the $\chi^{2}$ test.

\section{Results}

Table 1 shows the overall error frequency of errors for the four journals analysed was $119 / 400(29.7 \%)$, of which we considered $8 / 400$ as major $(2 \%)$, and $111 / 400(27.7 \%)$ as minor. Analysis of each journal was as follows: Acta Paediatr 36\%, Arch Dis Child 22\%, J Pediatr $29 \%$, Pediatrics $32 \%$, with a major error frequency of $1 \%, 1 \%, 2 \%$, and $4 \%$, respectively. The difference between Acta Paediatr and Arch Dis Child, both in the overall rate of errors (36 $v 22 \%)$ and in the frequency of minor errors (35 v 21\%) was significant ( $\mathrm{p}<0.05)$. Considering the eight major errors found, two were a wrongly quoted publishing year, three a wrong volume number, and three an error in the initial page. Among the minor mistakes, the most common was in the name or the authors' initials $(62 \%)$, followed by the article's title $(35.6 \%)$. There was a single error in 83 cases $(20.7 \%) ; 24$ references had two errors $(6 \%)$, and $12(3 \%)$ had three or more mistakes. The highest number of errors found was six for a single reference.

\section{Discussion}

The overall error rate is one of the lowest reported, and is similar to a study published in a general medicine journal where the authors evaluated five leading journals, finding a mean value of $26.5 \%$ and a range of $4.1-40.3 \% .{ }^{4}$ Our rate is significantly different from the highest rate reported- $60.7 \%$ in three gynaecological/ obstetrics journals. ${ }^{1}$ Regarding major errors, the rate was one of the two lowest reported, with an identical result to that published in an analysis of two Asian journals. ${ }^{3}$ Major mistakes are the most important as they make access to the reference difficult. ${ }^{1-3}$ Minor errors might be considered as a sign of disrespect or lack of courtesy to the author or authors, and may impact negatively on their academic records by excluding the name(s) from the citation index. ${ }^{5}$

Strategies proposed to lower errors are: (a) direct consultation with the original work or obtaining this work from a computerised database, rather than copying them from another citation; (b) writing the title and name of the authors in the language of their native country; (c) limiting the number of references ${ }^{5}$; and (d) submitting the first page of each of the referenced articles with the manuscript. Furthermore, editorial boards should make publishing requirements more stringent, because there is an association between the journal impact index and the number of errors. ${ }^{5}$

1 Roach VJ, Lau TK, Ngan Kee WD. The quality of citations in major international obstetrics and gynecology journals. Am F Obstet Gynecol 1997;177:973-5. 
2 McLellan MF, Case LD, Barnett MC. Trust, but verify. The accuracy of references in four anesthesia journals. Anesthesiology 1992;77:185-8.

Lee SY, Lee JS. A survey of reference accuracy in two Asian dermatologic journals (the Journal of Dermatology and the Korean Journal of Dermatology). Int F Dermatol 1999;38: $357-60$.
4 Siebers R, Holt S. Accuracy of references in five leading

medical journals. Lancet 2000;356:1445. Fenton JE, Brazier H, De Souza A, et al. The accuracy of citation and quotation in otolaryngology/head and neck surgery journals. Clin Otolaryngol 2000;25:40-4.

6 Schulmeister L. Quotation and reference accuracy of three nursing journals. Image f Nurs Sch 1998;30:143-6.

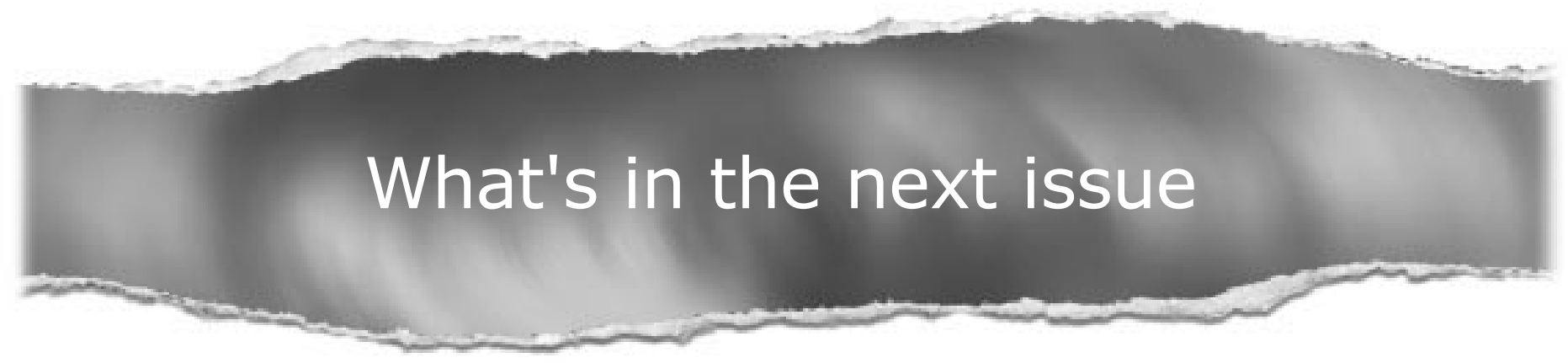

\section{Future content}

See which articles have just been accepted for publication and preview the table of contents for the next issue a month before it is published

\section{www.archdischild.com}

